STUDI

FRANCESI

\section{Studi Francesi}

Rivista quadrimestrale fondata da Franco Simone

169 (LVII | I) | 2013

LA RÉVOLUTION SUR SCÈNE a cura di Pierre Frantz, Paola Perazzolo, Franco Piva

\title{
Vittorio Fortunati, Fortunati, Burlesco, teatralità e galanteria nelle opere in prosa di Scarron
}

\section{Laura Rescia}

\section{(2) OpenEdition}

\section{Journals}

Edizione digitale

URL: http://journals.openedition.org/studifrancesi/3383

DOI: 10.4000/studifrancesi.3383

ISSN: 2421-5856

Editore

Rosenberg \& Sellier

\section{Edizione cartacea}

Data di pubblicazione: 1 aprile 2013

Paginazione: 165-166

ISSN: 0039-2944

\section{Notizia bibliografica digitale}

Laura Rescia, «Vittorio Fortunati, Fortunati, Burlesco, teatralità e galanteria nelle opere in prosa di Scarron », Studi Francesi [Online], 169 (LVII | I) | 2013, online dal 30 novembre 2015, consultato il 18 septembre 2020. URL : http://journals.openedition.org/studifrancesi/3383 ; DOI : https://doi.org/10.4000/

studifrancesi.3383

\section{Questo documento è stato generato automaticamente il 18 settembre 2020.}

\section{(i) (9)}

Studi Francesi è distribuita con Licenza Creative Commons Attribuzione - Non commerciale - Non opere derivate 4.0 Internazionale. 


\title{
Vittorio Fortunati, Fortunati, Burlesco, teatralità e galanteria nelle opere in prosa di Scarron
}

\author{
Laura Rescia
}

\section{NOTIZIA}

VITTORIO FORTUNATI, Burlesco, teatralità e galanteria nelle opere in prosa di Scarron, Roma, Bulzoni, 2011, pp. 129.

1 Questo saggio riunisce i contributi dedicati all'opera in prosa di Scarron che Fortunati ha pubblicato in un considerevole arco temporale - dal 1989 al 2010 - e ai quali si è aggiunto un capitolo inedito.

2 Il primo capitolo, dedicato alla precisazione del concetto di burlesco, propone per Scarron un'estensione della nozione che include le strategie d'intervento d'autore: queste nei romans comiques (come è stato peraltro già notato per l'opera di Sorel) svolgono una doppia funzione, con lo svelamento dell'illusione di realtà quale congegno di sollecitazione della coscienza critica del lettore. Viene successivamente proposto uno studio sulla dimensione teatrale del Roman comique, non solo e non tanto volta a sottolineare la ben nota presenza dell'espressione teatrale e della vita dei comici nel testo, quanto a svelare la dimensione spettacolare dell'opera barocca: un'evocazione del concetto barthesiano di théâtralité e dei successivi sviluppi critico-teorici avrebbe consentito ancor meglio all'autore di discutere le sue pertinenti osservazioni. Dopo un capitolo dedicato allo Scarron novelliere all'interno e all'esterno del Roman comique, e a riflessioni sugli incerti confini tra romanzo breve e novella, Fortunati dedica due saggi, di taglio comparatistico, ad una messa in prospettiva intertestuale del romanzo scarroniano: l'uno evoca i contatti con Apuleio, l'altro, recente e particolarmente innovativo, con l'Orlando Furioso. Di particolare interesse l'ultimo contributo, dedicato alle lettere e ai contatti stilistici tra queste e la più nota opera romanzesca. 
3 All'agilità della forma - l'autore non ama broder, andando dritto al centro della sua argomentazione - si associano chiarezza espressiva e un gusto particolare per la scelta citazionale: doti queste che, unite alla visione d'insieme che questo testo offre, rendono il libro utile tanto allo studioso quanto allo studente. 